Marquette University

e-Publications@Marquette

$9-1-1991$

\title{
Chronic Dermal Ulcer Healing Enhanced with Monophasic Pulsed Electrical Stimulation
}

Jeffery A. Feedar

Omni Therapy, Inc.

Luther C. Kloth

Marquette University, luther.kloth@marquette.edu

Gary D. Gentzkow

Staodynamics Inc

Published version. Physical Therapy, Vol. 7, No. 9 (September 1991): 639-649. DOI. (C) 1991 American Physical Therapy Association. Used with permission. 


\section{Chronic Dermal Ulcer Healing Enhanced with Monophasic Pulsed Electrical Stimulation}

The purposes of tbis randomized, double-blind, multicenter study were to compare bealing of cbronic dermal ulcers treated with pulsed electrical stimulation witb healing of similar wounds treated with sham electrical stimulation and to evaluate patient tolerance to the therapeutic protocol. Forty-seven patients, aged 29 to 91 years, with 50 stage II, III, and $I V$ ulcers were randomly assigned to either a treatment group $(n=26)$ or a control (sham treatment) group $(n=24)$. Treated wounds received 30 minutes of pulsed cathodal electrical stimulation twice daily at a pulse frequency of 128 pulses per second (pps) and a peak amplitude of $29.2 \mathrm{~mA}$ if the wound contained necrotic tissue or any drainage that was not serosanguinous. A saline-moistened nontreatment electrode was applied 30.5 $\mathrm{cm}$ (12 in) cephalad from the wound. This protocol was continued for 3 days afier the wound was debrided or exbibited serosanguinous drainage. Theneafter, the polarity of the treatment electrode on the wound was changed every 3 days until the wound progressed to a stage II classification. The pulse frequency was then reduced to 64 pps, and the treatment electrode polarity was changed daily until the wound was bealed. Patients in the control gnoup were treated with the same protocol, except they received sham electrical stimulation. After 4 weeks, wounds in the treatment and control gnoups were $44 \%$ and $67 \%$ of their initial size, respectively. The bealing rates per week for the treatment and control groups were $14 \%$ and $8.25 \%$, respectively. The results of this study indicate that pulsed electrical stimulation has a beneficial effect on bealing stage $I I, I I I$, and IV chronic dermal ulcers. (Feedar JA, Kloth LC, Gentzkow GD. Chronic dermal ulcer bealing enhanced with monopbasic pulsed electrical stimulation. Pbys Ther. 1991;71:639-649.)

Koy Wordst Dermal ulcers, Electrical stimulation, Ischemic ulcers, Wound bealing

\author{
Jefirey A Feedar \\ Luther C Kloth \\ Gary D Gentzkow
}

IA Feedar, BS, PT, is Director and Vice President, Wound Care Resources $1 n c_{1}$ and Director and President, Preferred Physical Therapy Services of W/isconsin SC, 8320 W Bluemound Rd, Ste 213, Milwaukee, WI 53213. He was Director of Therapy Services, Omni Therapy lic, 1810 Kensington Dr. Waukesha, WI 53188, when this study was conducted

LC Kloch, MS, PT, is Associate Professor, Program in Physical Therapy, Marquette University, Mi]waukee, WI 53233-2269 (USA); President, Wound Care Resources Inc; and Vice President, Preferred Physical Therapy Services of Wisconsin SC. Address all correspondence to Mr Kloth at the first address.

GD Genlzkow, MD, is Vice President and Medical Director, Staodynamics Inc, 1225 Florida Ave, PO Box 1379, Longmont, CO 80502-1379.

The results of this study were presented at the Annual Conference of the American Physical Therapy Association, Anaheim, $\mathrm{CA}$, June $24-28,1990$, and at the 1 th Intemational Congress of the World Confederation for Physical Therapy, London, United Kingdom, July 28-August 2, 1991.

This study was approved by the institulional review boards of the nine investigative centers involved and was supported by a grant from Staodynamics inc.
Since the mid-1900s, therapeutic doses of electrical current have been shown to augment healing of chronic wounds in human subjects and induced wounds in animal models. ${ }^{1-3}$ Studies of cell cultures have shown that electrical fields can influence the migratory, proliferative, and functional capacity of cells involved in the healing process. .14 $^{-1}$ Other studies have reported measurements of injury potentials, skin battery voltages, and wound lateral voltage gradients that have been theorized to trigger bioelectrical repair and enhancement of 
wound healing. 15,16 If electrical signals play a role in the stimulation of wound repair, then exogenous application of electrical current to chronic wounds could be expected to mimic the body's bioelectrical currents and enhance tissue healing processes. Reports from numerous clinical and experimental studies provide evidence in support of this idea. ${ }^{1-14}$

Since 1969 , a number of publications related to the clinical use of electrical stimulation for treatment of chronic dermal ulcers have reported accelerated rates of healing of $13 \%$ to $46 \%$ per week during an average of 6.6 weeks compared with small numbers of control wounds that healed between $5 \%$ and $15 \%$ per week. ${ }^{1-4}$ In all of these studies, the polarity of the wound electrode was changed periodically during the study period. Two of these studies reported using either 4 hours ${ }^{3}$ or 45 minutes $^{4}$ of electrical stimulation treatment per day, 5 days per week; the other two studies reported using 6 hours of stimulation per day, 7 days per week. ${ }^{1,2}$ All of these studies delivered 200 to 1,000 $\mu A$ of either direct current ${ }^{1-3}$ or timeaveraged pulsed current ${ }^{4}$ to the wound tissues.

Additional support for using direct current or time-averaged pulsed current electrical stimulation to accelerate healing of chronic dermal ulcers is provided by the results of numerous animal studies. Although there is lack of agreement on the effects of polarity, many of these studies have reported that electrical stimulation from direct current ${ }^{5-7}$ and timeaveraged pulsed current devices ${ }^{y}$ produces faster closures-8 and greater tensile strength of the scar tissue in acute induced wounds than in control wounds. Other experimental animal studies ${ }^{15-18}$ have confirmed that weak cathodal electrical stimulation solubilizes clotted blood, which provides support for the clinical observation that cathodal direct current stimulation facilitates debridement of necrotic wound tissue consisting primarily of coalesced blood elements. Recently, studies on induced wounds in pigs have reported that electrical stimulation can improve the survival of skin flaps ${ }^{19}$ and significantly increase the rate of wound epithelializa$t^{1} \mathrm{n}^{7}$ and contraction ${ }^{20.21}$ and the proliferation of fibroblasts. ${ }^{20}$

Some of these findings are in turn supported by in vitro studies in which isolated epidermal cells, cell clusters, and cell sheets demonstrated galvanotaxis in migrating toward the cathode. ${ }^{9,10}$ A galvanotaxic effect on other cells involved in the tissue-healing process has been demonstrated in a number of other studies as well. Macrophages have been shown to migrate toward the anode ${ }^{11}$ whereas neutrophils have been observed to migrate toward both the anode and the cathode. ${ }^{12,13}$ Monguio $^{12}$ and Dineur, ${ }^{14}$ however, have reported that neucrophilic leukocytes migrate toward the cathode in regions in which infection or inflammation are present, and Eberhardt et $\mathrm{al}^{22}$ have found that electrical stimulation increases the relative number of neutrophilic leukocytes in human skin exudate. Weiss et al ${ }^{23}$ have indicated that, following exposure to exogenous current, there is evidence of a reduction in human tissue mast cells. Such cells are present in increased numbers in a variety of fibrotic disorders including keloids. ${ }^{23}$ Weiss and colleagues speculate that the effect of electrical stimulation on scar formation may be due to a decrease in mast cell migration.

That cell functional capacity may be influenced by changes in potential is supported by cell culture studies in which erythrocytes and fibroblasts were exposed to electrical currents. Harrington and Becker ${ }^{24}$ have shown that frog erythrocytes subjected to electrical current synthesize ribonucleic acid and protein, whereas erythrocytes not exposed to current do not produce appreciable amounts of macromolecules. In view of the significant differences berween human and frog erythrocytes, this effect may not relate to the clinical use of electrical stimulation. Bassett and Herrmann ${ }^{25} \mathrm{ex}$ posed Green's 3T- 6 fibroblasts in culture to continuous direct current and demonstrated increases in deoxyribonucleic acid (DNA) production and collagen synthesis after 14 days. By internupting the direct current, they found that DNA production increased $20 \%$ and that collagen synthesis in. creased $100 \%$.

Bourguignon and Bourguignon ${ }^{26}$ repored that high voltage pulsed current stimulation of normal human fibroblasts in culture led to increased DNA production and protein synthesis. Maximum synthesis was noted to occur in cells lying in close proximity to the cathode. This observation is consistent with previous evidence linking a proliferative response to electronegativity.

Growth factors play an important role in wound healing, and the transformation of growth factor- $\beta$ has a fundamental role in collagen synthesis. Falanga et $a^{27}$ have demonstrated that dermal fibroblasts in culture, stimulated with pulsed current at 100 pulses per second (pps) and $100 \mathrm{~V}$, had increases in the expression of receptors for transforming growth factor- $\beta$ that were six times greater than those of control fibroblasts.

The effects of exogenous currents on wound tissues and cells may enhance the effects of the "skin battery," which is believed to reside within the epidermis and to augment wound healing. Foulds and Barker ${ }^{28}$ have demonstrated that a voltage is maintained across the epidermis. They report that the outer surface of skin is negatively charged with respect to the positively charged dermis. The average voltage measured on the surface of human skin is $-23.4 \mathrm{mV} .{ }^{15}$ In wounded mammalian skin, wound currents have been shown to generate lateral intraepidermal voltage gradients surrounding the wound as a very nartow $1-\mathrm{mm}$ band. ${ }^{16}$ At $0.25 \mathrm{~mm}$ from the wound edge, the amplitude of this voitage gradient falls off about threefold. ${ }^{29}$ Interestingly, corresponding decreases in epidermal cell migration also occur a very short distance from the wound edge. 
The purposes of this clinical study were (1) to compare healing of chronic dermal ulcers treated with pulsed electrical stimulation with healing of similar wounds treated with sham electrical stimulation and (2) to evaluate patient tolerance to the therapeutic protocol. We hypothesized that chronic dermal ulcers treated with pulsed electrical current would heal faster and more completely than ulcers treated with sham electrical stimulation.

\section{Method}

\section{Subjects}

Fifty-nine patients (67 wounds) at nine investigational sites participated in the study. Eight patients each had 2 wounds, which were separately randomized and entered into the study. Of the initial 59 patients, the data for 12 patients (17 wounds) were not included in the data analysis. Four wounds were excluded because the patients did not complete the 4 -week study, 4 because the wound size did not meet entry criteria, 3 for uninterpretable measurements, and 6 because of omitted or incorrect treatments. The data for the remaining 47 patients (50 wounds 26 in the treatment group, 24 in the control group]) were thus available for the data analysis.

Patient ages ranged from 29 to 91 years. The mean ages of the patients in the treatment and control groups were $66.6(\mathrm{SD}=15.6)$ and 60.7 (SD $=19.2$ ) years, respectively. The patients ( $52 \%$ male, $48 \%$ female) were equally distributed berween the treatment and control groups (Tab. 1).

The subjects in this study were patients with stage II, III, or IV chronic dermal ulcers. There were no age or sex restrictions for participation in the study. The patients were participants in the study for 4 weeks, because we believed that some measurable effect on healing would occur in that amount of time. Patients were excluded from the study if they had cardiac pacemakers, peripheral vascular disease disposing them to thrombosis, or active osteomyelitis or if they were

Table 1. Patient and Ilcer Characteristics

\begin{tabular}{|c|c|c|c|}
\hline & $\begin{array}{l}\text { Control Group } \\
(n=24)\end{array}$ & $\begin{array}{l}\text { Treatment } \\
\text { Group } \\
\text { (n=26) }\end{array}$ & Total \\
\hline \multicolumn{4}{|l|}{ Age $(y)$} \\
\hline $\bar{x}$ & 60.7 & 66.6 & 63.8 \\
\hline SO & 19.2 & 15.6 & 17.5 \\
\hline Range & $30-90$ & $29-91$ & $29-91$ \\
\hline \multicolumn{4}{|l|}{$\operatorname{Sex}(\%)$} \\
\hline Male & 50.0 & 538 & 52.0 \\
\hline Fernale & 50.0 & 46.2 & 48.0 \\
\hline \multicolumn{4}{|l|}{ Stage } \\
\hline$\|$ & 2 & 0 & 2 \\
\hline III & 17 & 22 & 39 \\
\hline IV & 5 & 4 & 9 \\
\hline Total & 24 & 26 & 50 \\
\hline \multicolumn{4}{|l|}{ Etiology } \\
\hline Pressure sore & 18 & 17 & 35 \\
\hline Surgical & 3 & 6 & 9 \\
\hline Vascular & 1 & 0 & 1 \\
\hline Traumatic & 2 & 3 & 5 \\
\hline Total & 24 & 26 & 50 \\
\hline \multicolumn{4}{|l|}{ Location } \\
\hline Hip/ischium & 6 & $\mathrm{~g}$ & 14 \\
\hline Sacrum/coccyx & 9 & 4 & 13 \\
\hline Leg & 1 & 5 & 6 \\
\hline Foot & 6 & 5 & 11 \\
\hline Other ${ }^{a}$ & 2 & 4 & 6 \\
\hline Total & 24 & 26 & 50 \\
\hline \multicolumn{4}{|l|}{ Duration (\%) } \\
\hline$<1 \mathrm{mo}$ & 20.8 & 23.1 & 22.0 \\
\hline $1-3$ mo & 16.7 & 26.9 & 22.0 \\
\hline $3-6 \mathrm{mo}$ & 16.7 & 7.7 & 12.0 \\
\hline $6-12 \mathrm{mo}$ & 25.0 & 23.1 & 24.0 \\
\hline$>12 \mathrm{mo}$ & 20.8 & 19.2 & 20.0 \\
\hline
\end{tabular}

${ }^{a}$ Head, back, axilla

pregnant or receiving long-term radiation therapy, steroid therapy, or chemotherapy. Following the initial evaluation to determine whether the wound and the patient met the selection criteria, each patient signed an informed consent form. Patients were then randomly assigned to either an electrical stimulation treatment group or a control (sham electrical stimulation) group

\section{Wound Selection}

Wounds could be stage II, III, or IV pressure sores; ulcers caused by vascular insufficiency; or wounds caused by trauma or surgery. The wound stages were defined as follows: stage II wounds =full-thickness skin defects extending into the subcutaneous tissue; stage III wounds=defects extending into the muscle; and stage IV wounds $=$ defects extending into the bone or the joint ${ }^{30}$ Wounds could be 


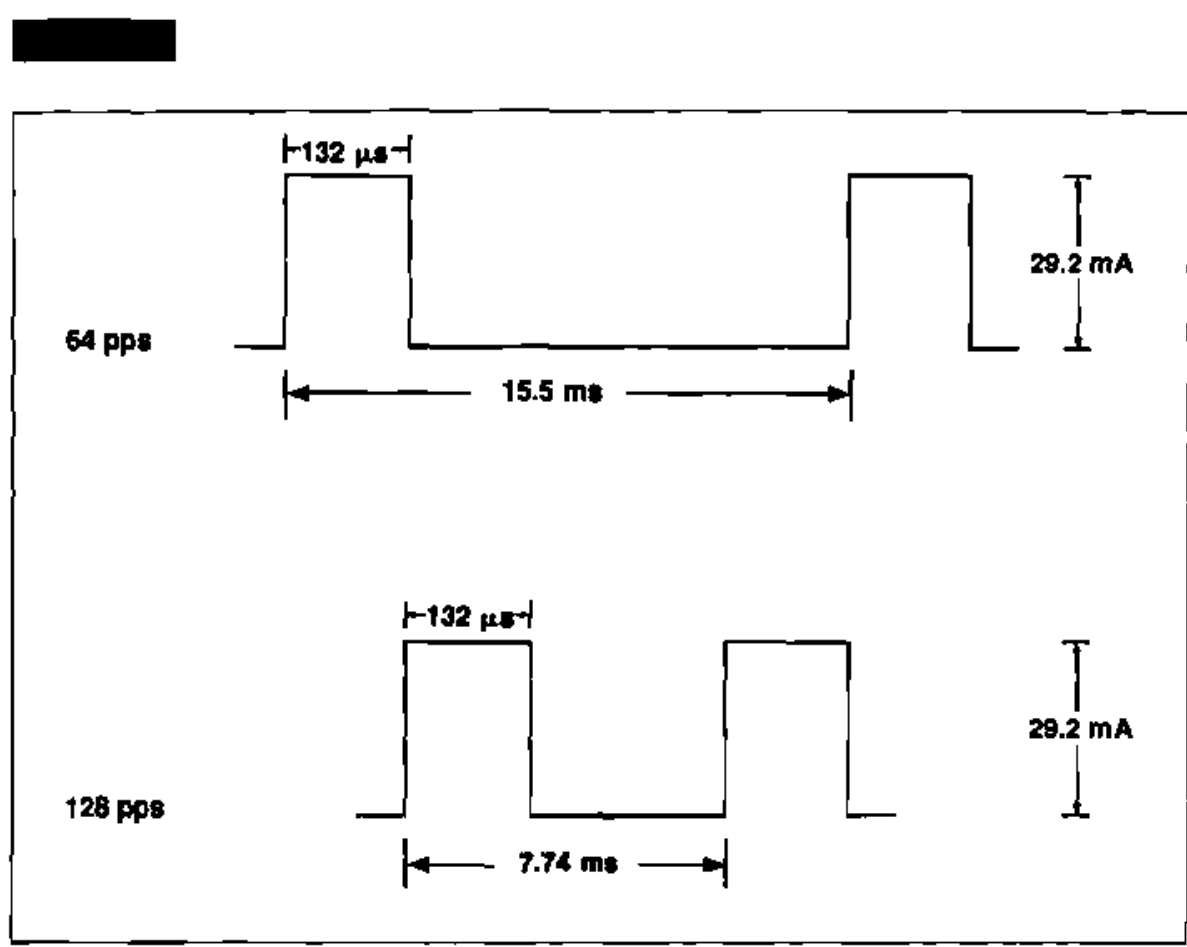

Figure 1. Duration and amplitude characteristics of the monopbasic pulsed cur. rent at frequencies of 64 and 128 pulses per second (pps). between 4 and $100 \mathrm{~cm}^{2}$ in size. Wounds excluded from the study were those with uninterpretable measurements (ie, measurements obtained when investigators were inconsistent in how they measured the wound) and those that were completely occluded by eschar, those that were hemorrhaging, or those of cancerous etiology.

Of the 50 wounds represented in the data analysis, 2 were stage II wounds, 39 were stage III wounds, and 9 were stage IV wounds (Tab. 1). Both stage II wounds were in the control group. Table 1 also shows the etiology, location, and duration of all ulcers. The etiologies of the wounds ( 35 pressure sore, 9 surgical, 1 vascular, and 5 traumaric) were approximately equivalent in the two groups. The locations of the ulcers were hip/ischium $(n=14)$, sacrum/coccyx $(n=13)$, leg $(n=6)$, foot $(n=11)$, and other $(n=6)$, and these locations were approximately equally distributed in the two groups. Duration of the uicer was also equiva- lent in the groups (ie, $22 \%=<1$ month, $22 \%=1-3$ months, $12 \%=3-6$ months, $24 \%=6-12$ months, and $20 \%=>1$ year). Initial wound size was a mean of $14.64 \mathrm{~cm}^{2}$ in the treatment group and $16.93 \mathrm{~cm}^{2}$ in the control group. There were more patients with tunnels or undermining in the treatment group than in the control group (26.9\% versus $16.7 \%$, respectively). There were no significant differences $(P<10)$ between the treatment and control groups for any of the patient, ulcer, or wound care characteristics. Therefore, the randomization procedure appears to have successfully provided comparable treatment and control groups.

\section{Instrumentation}

The electrical stimulation device used in this study was the Vara/Pulse stimulator, ${ }^{*}$ which delivers monophasic pulsed current. (Nore: the Vara/Pulse stimulator is no longer commercially available.) A Tektronix model 2430 digital oscilloscope ${ }^{\dagger}$ was used to pass
'Staodynamics Inc, 1225 Florida Ave, PO Box 1379, Lengmont, CO 80502-1379.

${ }^{\dagger}$ Tektronix Inc, PO Box 500, Beaverton, OR 97077. the output pulse through a $1-\mathrm{k} \mathbf{\Omega}$ load at $29.2 \mathrm{~V}$ (output dial set at 35 ). The output pulse was observed to have instantaneous rise and decay times of the waveform Icading and trailing edges, resulting in a rectangular pulse with an amplitude of $29.2 \mathrm{~mA}$ and a duration of $132 \mu s$. At this resistive load, the current per pulse delivered to the stainless steel, sponge-covered electrodes of the active stimulators was $3.9 \mu \mathrm{C}$. For the purpose of this study, pulse frequencies of 128 and 64 pps were used. At these frequencies, the pulse period was determined to be 7.74 and $15.5 \mathrm{~ms}$, respectively (Fig. 1). Thus, the accumulated pulse charge was $499.2 \mu \mathrm{C} / \mathrm{s}$ at the higher pulse frequency and $249.6 \mu \mathrm{C} / \mathrm{s}$ at the lower frequency.

\section{Procedure}

This study was conducted as a randomized, double-blind clinical trial. First, a randomization list was established for each center by the central study director. Each consecurive numbered patient at each center was then randomly assigned to either a treatment group, which used an active stimulator, or a control group, which used a stimulator that had been modified to produce no output current. The randomization procedure was controlled to ensure that equal numbers of patients were assigned to the treatment and control groups at each center. The clinical investigators did not have access to the randomization lists and therefore did not know whether a particular device was active or inactive. Neither the investigators nor the parients were aware of which type of device was used for a particular wound during the 4-week study period. Patients in the treatment and control groups received identical treatments during the study period, except for the type of stimulator (ie, active versus inactive) that was used.

A few patients reported a tingling sensation; however, this sensation was reported by patients in both groups, and we do not believe that it compromised the blinding procedure. Al] investigators agreed to comply with the blinding procedure, and monitor- 
Table 2. Summary of Wound Length-Width Products for Patients in Electrical Stimulation Treatment Group $(n=26)^{a}$

\begin{tabular}{|c|c|c|c|c|c|c|c|}
\hline \multirow{2}{*}{$\begin{array}{l}\text { Wound } \\
\text { No. }\end{array}$} & \multirow{2}{*}{$\begin{array}{l}\text { Inltial Wound SIze } \\
\left(\mathrm{cm}^{2}\right)\end{array}$} & \multicolumn{5}{|c|}{ Percentage of Inltial Longth-Whdth Product } & \multirow{2}{*}{$\begin{array}{l}\text { Total No. } \\
\text { of Weeks }\end{array}$} \\
\hline & & Week 1 & Wook 2 & Week 3 & Week 4 & Lost Week & \\
\hline TR-01 & 5.00 & 75.00 & 75.00 & 75.00 & 72.00 & 12.00 & 15 \\
\hline TR-02 & 15.64 & 62.66 & 35.17 & 21.74 & 10.55 & 1.60 & 7 \\
\hline TR-03 & 21.50 & 87.72 & 88.88 & 102.00 & 92.09 & 70.70 & 14 \\
\hline TR-04 & 44.00 & 93.81 & 75.00 & 54.09 & 39.45 & 5.09 & 8 \\
\hline TR-05 & 8.64 & 100.00 & 81.48 & 41.67 & 6.94 & 2.78 & 5 \\
\hline TR-06 & 6.00 & 33.33 & 30.00 & 8.33 & 4.17 & 4.17 & 4 \\
\hline TA-07 & 35.38 & 62.41 & 21.20 & 17.67 & 1.41 & 0.06 & 10 \\
\hline TR-08 & 7.00 & 85.00 & 91.14 & 87.43 & 75.00 & 0.71 & 15 \\
\hline TR-09 & 5.85 & 76.92 & 85.47 & 51.28 & 68.38 & 68.38 & 4 \\
\hline TR-10 & 9.89 & 84.52 & 54.60 & 17.69 & 0.40 & 0.40 & 4 \\
\hline TR-11 & 4.00 & 58.50 & 28.00 & 31.50 & 21.00 & 2.50 & 7 \\
\hline TR-12 & 4.60 & 66.52 & 33.91 & 45.65 & 48.04 & 48.04 & 4 \\
\hline TR-13 & 12.50 & 100.00 & 68.00 & 57.60 & 70.56 & 12.00 & 14 \\
\hline TR-14 & 4.80 & 76.67 & 54.17 & 31.25 & 15.63 & 12.50 & 8 \\
\hline TR-15 & 40.50 & 95.56 & 90.25 & 92.37 & 6644 & 25.93 & 8 \\
\hline TR-16 & 5.44 & 94.12 & 77.21 & 82.72 & 62.13 & 62.13 & 4 \\
\hline TF-17 & 16.25 & 59.08 & 40.62 & 15.88 & 4.62 & 0.37 & 6 \\
\hline TR-18 & 4.95 & 75.76 & 24.24 & 45.45 & 34.14 & 34.14 & 4 \\
\hline TR-19 & 8.00 & 78.75 & 80.00 & 75.00 & 75.00 & 50.00 & 8 \\
\hline TR-20 & 9.00 & 75.00 & 35.56 & 31.11 & 18.33 & 18.33 & 4 \\
\hline TR-21 & 22.80 & 88.33 & 105.61 & 154.61 & 62.72 & 0.00 & 12 \\
\hline TR-22 & 21.00 & 100.00 & 77.38 & 74.57 & 49.71 & 35.00 & 14 \\
\hline TR-23 & 18.45 & 95.39 & 82.38 & 65.04 & 66.40 & 57.13 & 5 \\
\hline TR-24 & 17.39 & & 60.72 & 31.74 & 19.84 & 19.84 & 4 \\
\hline TA-25 & 28.00 & 125.00 & 125.00 & 100.00 & 87.50 & 0.00 & 15 \\
\hline TA-26 & 4.20 & 94.29 & 94.29 & 68.57 & 68.57 & 68.57 & 4 \\
\hline $\bar{x}$ & 14.65 & $\overline{81.77}$ & 65.97 & $\overline{56.92}$ & 43.89 & 23.55 & 7.96 \\
\hline SD & 11.37 & 18.28 & 27.34 & 33.37 & 29.47 & 24.95 & 4.13 \\
\hline$N$ & 26 & 25 & 26 & 26 & 26 & 26 & 26 \\
\hline
\end{tabular}

${ }^{a}$ Note: Initial wound size is given as length-width product (in square cenlimeters). Weckly measurements are given as the percentage of the initial wound size.

ing did not reveal any evidence that this procedure had been compromised. To further ensure that the clinical trials were blinded, the persons who administered the treatments were different from those who obtained the measurements. To ensure consistency of the measurement technique across clinical sites, a nurse specialist trained all of the personnel who obtained the measurements and monitored all clinical sites during the study by periodic site visitations. Furthermore, the same person at each clinical site took all of the measurements on a given patient throughout the srudy.

Each wound was assessed at the beginning of the srudy before the active or sham stimulation protocol was begun. A wound/patient clinical history, including wound etiology, prior treatment received, and medications being taken, was recorded. Wound duration information was obtained by patient self-report when not available from patient records.
Once a week, the wound appearance (eg, color, presence or absence of necrotic and/or granulation tissue) was documented, and length and width measurements of the wound were recorded. A color photograph was taken every 2 weeks to provide a permanent record and for monitoring purposes. The length of the wound was recorded as the wound's largest diameter, and the width of the wound was recorded as the wound's largest diameter perpendicular to the length. This measurement technique is sim- 
Table 3. Summary of Wound Length-Width Products for Patients in Sbam Trearment Gnoup $(n=24)^{a}$

\begin{tabular}{|c|c|c|c|c|c|}
\hline \multirow{2}{*}{$\begin{array}{l}\text { Wound } \\
\text { No. }\end{array}$} & \multirow{2}{*}{$\begin{array}{l}\text { Inhtial Wound Slze } \\
\left(\mathrm{cm}^{2}\right)\end{array}$} & \multicolumn{4}{|c|}{ Percentage of Initial Length-Whdth Product } \\
\hline & & Weak 1 & Week 2 & Week 3 & Weak 4 \\
\hline $\mathrm{SH}-01$ & 6.00 & 83.33 & 62.50 & 84.00 & 90.00 \\
\hline $\mathrm{SH}-02$ & 4.50 & 66.67 & 38.89 & 21.78 & 7.78 \\
\hline $\mathrm{SH}-03$ & 12.25 & & 45.71 & & 5.31 \\
\hline $\mathrm{SH}-04$ & 5.25 & 166.67 & 178.67 & 178.67 & 178.67 \\
\hline $\mathrm{SH}-05$ & 7.50 & 90.00 & 66.67 & 50.00 & 21.33 \\
\hline $\mathrm{SH}-06$ & 12.25 & 96.65 & 100.00 & 85.71 & 83.59 \\
\hline $\mathrm{SH}-07$ & 30.00 & 100.00 & 140.00 & 110.00 & 108.33 \\
\hline $\mathrm{SH}-0 \mathrm{~B}$ & 12.25 & 143.92 & 153.96 & 130.29 & 139.59 \\
\hline SH-OG & 6.40 & 61.25 & 26.56 & 3.28 & 0.00 \\
\hline $\mathrm{SH}-10$ & 74.70 & 94.65 & 96.72 & 78.98 & 81.39 \\
\hline $\mathrm{SH}-11$ & 67.50 & 88.15 & 57.04 & 38.30 & 6.40 \\
\hline $\mathrm{SH}-12$ & 8.40 & 95.24 & 72.38 & 53.57 & 29.76 \\
\hline $\mathrm{SH}-13$ & 5.10 & & 117.65 & 29.41 & 37.65 \\
\hline $\mathrm{SH}-14$ & 5.55 & 100.00 & 97.30 & 90.81 & 100.90 \\
\hline $\mathrm{SH}-15$ & 20.40 & & 80.88 & 81.57 & 66.18 \\
\hline $\mathrm{SH}-16$ & 40.00 & 78.75 & 60.00 & 64.12 & 28.13 \\
\hline $\mathrm{SH}-17$ & 5.28 & 87.12 & 79.55 & 57.95 & 51.52 \\
\hline $\mathrm{SH}-18$ & 4.05 & 98.77 & 72.59 & 57.78 & 65.68 \\
\hline SH-19 & 6.76 & 99.41 & 107.84 & 107.84 & 142.01 \\
\hline $\mathrm{SH}-20$ & 41.48 & 87.22 & 85.34 & 80.88 & 90.89 \\
\hline $\mathrm{SH}-21$ & 6.21 & 69.57 & 69.57 & 63.77 & 57.97 \\
\hline $\mathrm{SH}-22$ & 10.50 & 100.00 & 95.24 & 76.19 & 81.71 \\
\hline $\mathrm{SH}-23$ & 4.00 & 110.00 & & 45.00 & 38.50 \\
\hline $\mathrm{SH}-24$ & 10.00 & 100.00 & 90.00 & 90.00 & 99.00 \\
\hline$\overline{\bar{x}}$ & 16.93 & 96.06 & 86.74 & 73.04 & 67.18 \\
\hline SD & 19.79 & 23.51 & 36.09 & 37.54 & 47.32 \\
\hline $\mathrm{N}$ & 24 & 21 & 23 & 23 & 24 \\
\hline
\end{tabular}

"Note: Initial wound size is given as length-width product (in square centimeters). Weekly measurements are given as the percentage of the initial wound size.

ple, reproducible, and easy to accomplish at the bedside. In addition, evaluators were required to illustrate the position of these measurements on a wound diagram. Thus, the primary measure of wound healing used in the study was the measurement of wound size.

The protocol consisted of two 30minute active or sham electrical stimulation sessions, given 7 days a week. The protocol was based on those used in previous clinical studies ${ }^{-4}$ and consisted of the following steps:
1. Irrigation of the wound bed with saline solution before each treatment and maintenance of a salinemoistened wound environment between treatments.

2. Application of clean, salinemoistened gauze sponges directly over stage II wounds or into stage III and IV wounds.

3. Application of a $16 \cdot \times 16 \cdot \mathrm{cm}$ nontreatment sponge electrode moistened with tap water and secured to the skin a minimum of $30.5 \mathrm{~cm}$ (12 in) from the wound site.
4. Application of a $7.5-\times 7.5-\mathrm{cm}$ treatment sponge electrode on top of the saline-moistened gauze covering the wound and secured in place.

5. Vara/Pulse ${ }^{\text {st }}$ stimulation controls were set at a pulse frequency of $128 \mathrm{pps}$ and at an amplitude of 35 $\mathrm{mA}$, and the polarity switch was set to deliver a negative charge to the electrode placed on the wound.

6. Using these stimulus variables, two 30-minute treatments were given daily ( 7 days a week), with a mini- 


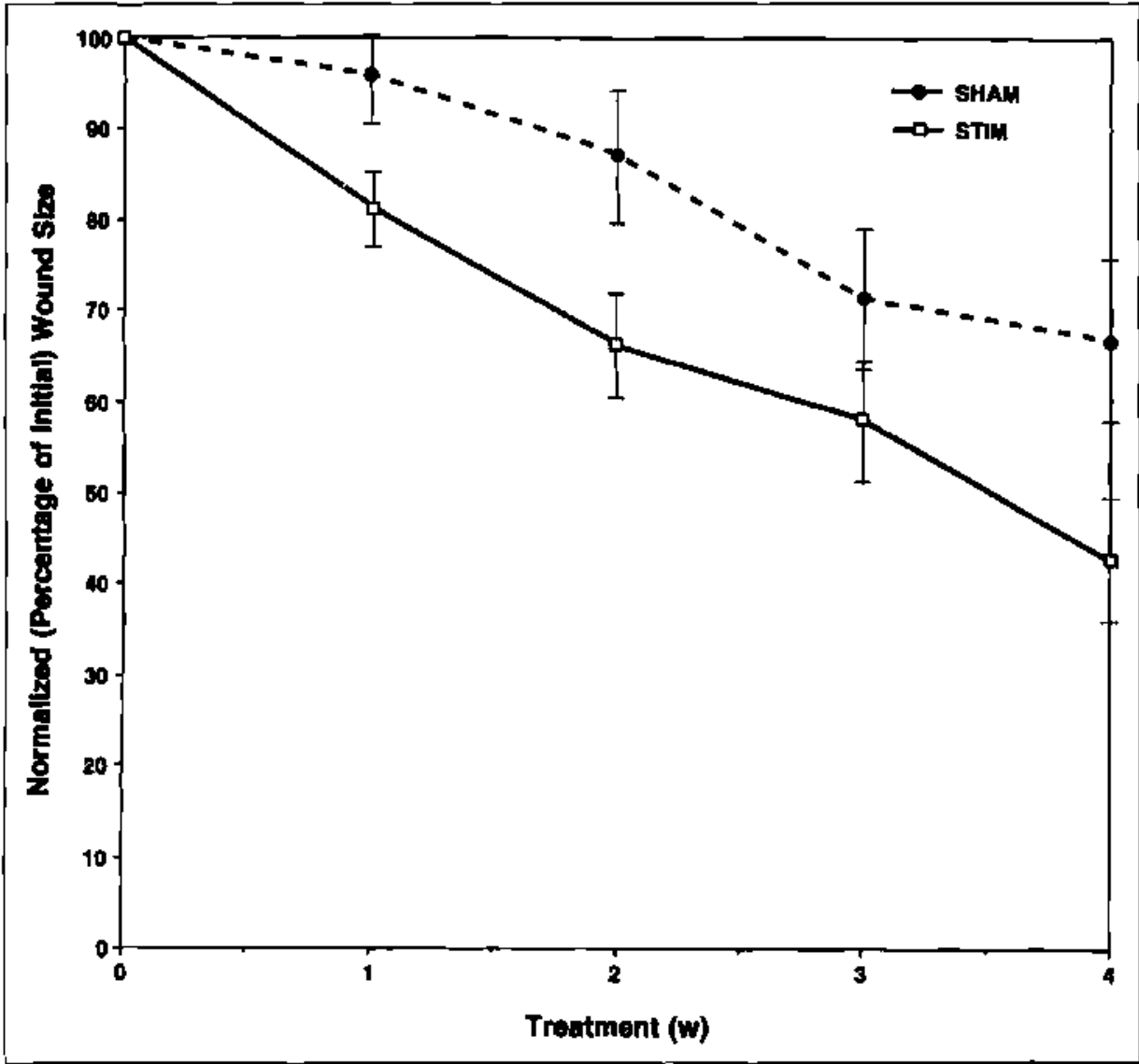

Figure 2. Mean percentage of reduction in wound size with standard error for each of 4 weeks of treatment for the electrical stimulation group (STIM) and the sham electrical stimulation group (SHAM).

mum of 4 hours and a maximum of 8 hours between treatment sessions.

7. In this study, only $10 \%$ of each group received surgical or whirlpool debridement. The wounds not requiring surgical or whirlpool debridement were treated with electrical stimulation or dressings (generally for about 7 days) until the wound spontaneously debrided or a serosanguinous drainage appeared. In either case, negative polarity of the wound electrode was continued for 3 additional days. Thereafter, the polarity of the wound electrode was changed every 3 days until the wound healed to a stage II classification. At that time, it was felt that an excessive charge delivered at 128 pps might overstimulate the wound tissue; therefore, the pulse frequency was decreased to 64 pps. In addition, the polarity of the wound electrode was alternated daily until the wound closed. On the average, polarity of the wound electrode was changed six times in the 28 day period.

8. If a wound initially was a clean stage II wound, treatment was started as described in step 7.

Patients residing in skilled nursing facilities were treated daily by a health care practitioner (ie, physical therapist, registered nurse, physician) who was a member of the study team for that facility. For outpatients who lived at home, either the patient or a family member was trained to apply the stimulator each day. Ejght patients in each group received their treatment as outpatients. In all instances, health care practitioners obtained the wound measurements each week. Evaluators who measured the wounds were unaware as to whether the electrical stimulator was an active or an inactive device.

Patients in the control group, after completing the 4-week trial, were then given the opportunity to switch to an active stimulator. Patients who chose to cross over to an active stimulator were monitored and treated in the same manner as during the preceding 4-week trial. The patients who received active electrical stimulation were treated for at least 4 weeks or until wound closure occurred. All patients' wounds were assessed at weekly intervals for 4 weeks after the study protocol was terminated.

\section{Data Analysis}

Data from the treatment and control groups were statistically analyzed to determine comparability of the groups with regard to factors that might influence outcome. We analyzed the following characteristics: sex, age, wound stage, wound duration, wound etiology, wound location, presence of tunnels or undermining, presence of eschar, initial wound measurements (length, width, and length-width product), patient mobility status (bedridden, wheelchair user, ambulatory), previous and concurrent treatments of wound, systemic conditions, concurrent treatment for other conditions, and inpatient versus outpatient treatment. The statistical analysis involved the use of the chi-square test (with the Yates continuity correc tion for fourfold tables) for discrete factors such as wound stage or location and the two-sample $t$ test for quantitative measures such as wound duration or initial size.

Wound length and width were measured at weekly intervals during the treatment period. Because wound measurement values were obtained for both treatment and control groups each week for 4 weeks, we used the wound size data (defined as the length-width product) at the 4-week point as the definitive data for comparison purposes. A reduction in the 

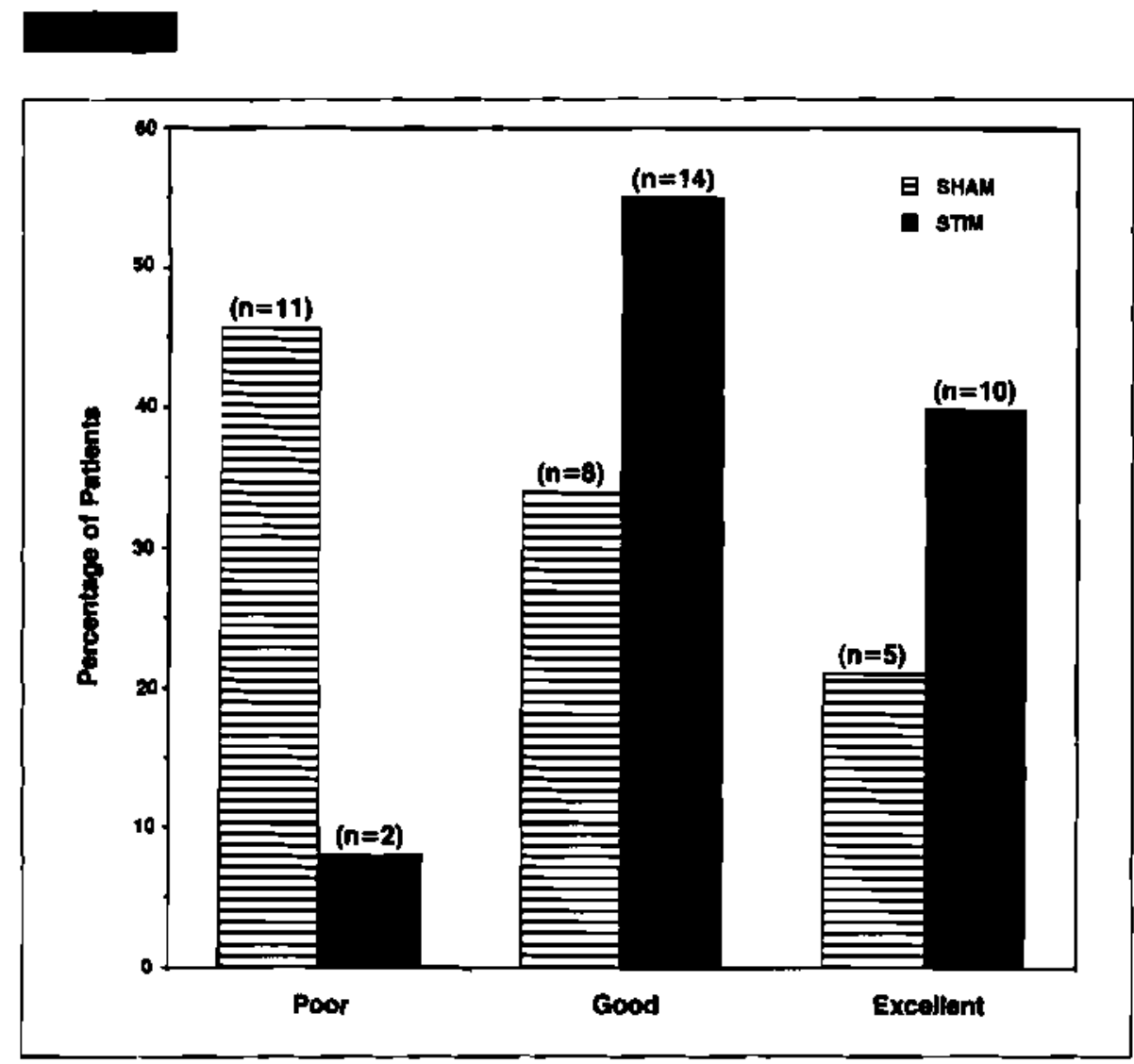

Flgure 3. Comparison of wound bealing in electrical stimulation group (STIM) and sham electrical stimulation group (SHAM) after 4 weeks of treatment.

length-width product was considered an indication of wound healing.

These changes in wound size were assessed by expressing each wound's length-width product at each week as a percentage of its initial length-width product, allowing comparisons of all wounds, regardless of their absolute size. The means of the individual percentages for each group's wounds were compared, using the two-sample $t$ test (one-tailed) to evaluate the null hypothesis of no treatment differences. For the patients in the control group who crossed over to active stimulation, a paired $t$ test (one-tailed) was used to compare the wound data obtained during the 4 weeks of active treatment with the wound data obtained during the 4 weeks of sham treatment. A stepwise multipleregression analysis was performed using the week-4 wound size as the dependent variable to evaluate the significance of treatment group in wound healing, while adjusting for other factors that might influence the outcome of wound healing.

\section{Result:}

Tables 2 and 3 present summaries of the wound length-width products during the course of the study for all wounds. The measurements for each week are expressed as a percentage of the initial wound size. After 4 weeks, the 26 wounds in the treatment group were $44 \%$ of their original size, whereas the 24 wounds in the control group were $67 \%$ of their initial size $(P<.02)$. These differences represent an average healing rate of $14 \%$ per week for the treatment group versus $8.25 \%$ per week for the control group. None of the treatment group's ulcers increased in size; 5 of the control group's ulcers increased in size. Figure 2 graphically demonstrates the substantial difference in healing between the groups

Only two variables, presence of tunnels or undermining $(P=.001)$ and treatment group $(P=.007)$, were found in the stepwise multipleregression analysis to be significantly $(P<, 05)$ associated with the week-4 wound size. The fitted model from this analysis indicates that the expected percentage of initial wound size after 4 weeks would be $45.7 \%$ (plus $43.2 \%$ if tunnels or undermining were present; minus $28.7 \%$ if they received active stimulation). That is, wounds would heal significantly less well if tunnels or undermining were present and significantly better if they received active stimulation. As noted previously, more of the wounds in the treatment group than in the control group had tunnels or undermining, indicating that, if there was a bias attributable to differences within the treatment group, it was against the active treatment.

For descriptive purposes only, we categorized the 4-week results according to the following classification, which did not lend itself to statistical analysis: excellent results-wound less than $25 \%$ of its initial size or completely healed, good resultswound between $25 \%$ and $75 \%$ of its initial size, and poor results-no change or wound greater than $75 \%$ of its initial size. Figure 3 shows that, at 4 weeks, a substantially higher proportion of the treatment group's ulcers (92\%) than of the control group's ulcers (54\%) could be categorized as good or excellent.

Fourteen of the wounds in the control group were crossed over to nonrandomized active electrical stimulation after the patients completed the 4 weeks of sham treatment (Tab. 4). After 4 weeks of sham treatment, these 14 wounds were $88.7 \%$ of their initial size and had healed at a rate of $2.9 \%$ per week. After 4 weeks of active electrical stimulation, these same wounds were $49 \%$ of their size at the time of crossover and had healed at a rate of $12.8 \%$ per week. The reduction in wound size was fourfold greater after receiving active stimulation $(P=.005)$. These wounds continued to be treated for a mean total trearnent time of 10.8 weeks; all wounds except 2 continued 
Table 4. Summary of Wound Lengtb-Width Products For Patients Who Crossed Over from Sham to Active Stimulation (n=14)

\begin{tabular}{|c|c|c|c|c|}
\hline $\begin{array}{l}\text { Wound } \\
\text { No. }\end{array}$ & $\begin{array}{l}\text { Percentage of } \\
\text { Initlal Slze After } 4 \\
\text { Woeks of Sham } \\
\text { Treatment }\end{array}$ & $\begin{array}{l}\text { Porcentage of Wound Sizo } \\
\text { at Crossover After } 4 \text { Weeks } \\
\text { of Active Stimulation }\end{array}$ & $\begin{array}{l}\text { Percentage of Wound Size at } \\
\text { Croseover Atter Last Week of } \\
\text { Active Stimulation }\end{array}$ & $\begin{array}{l}\text { Total No. of Woeks } \\
\text { of Actlve } \\
\text { Stimulation }\end{array}$ \\
\hline $\mathrm{SH}-01$ & 90.00 & 66.66 & 37.03 & 10 \\
\hline $\mathrm{SH}-\mathrm{O} 4$ & 178.67 & 32.00 & 6.40 & 15 \\
\hline $\mathrm{SH}-06$ & 83.59 & 26.37 & 0.00 & 7 \\
\hline $\mathrm{SH}-07$ & 108.33 & 79.26 & 61.54 & 10 \\
\hline $\mathrm{SH}-08$ & 139.59 & 98.25 & 85.96 & 7 \\
\hline $\mathrm{SH}-12$ & 29.76 & 10.00 & 0.00 & 5 \\
\hline $\mathrm{SH}-13$ & 37.65 & 36.46 & 47,40 & 8 \\
\hline $\mathrm{SH}-15$ & 66.18 & 74.07 & 13.63 & 11 \\
\hline $\mathrm{SH}-16$ & 28.13 & 17.78 & 0.00 & 10 \\
\hline $\mathrm{SH}-18$ & 65.68 & 7.89 & 0.00 & 7 \\
\hline $\mathrm{SH}-19$ & 142.01 & 52.50 & 0.00 & 13 \\
\hline $\mathrm{SH}-2 \mathrm{O}$ & 90.89 & 93.10 & 89.66 & 11 \\
\hline $\mathrm{SH}-22$ & 81.71 & 76.92 & 79.25 & 16 \\
\hline $\mathrm{SH}-24$ & 99.00 & 15.15 & 0.00 & 12 \\
\hline $\bar{x}$ & $88.66^{2}$ & $49.03^{a}$ & 30.06 & 10.80 \\
\hline SD & 42.16 & 30.83 & 34.53 & 3.07 \\
\hline$N$ & 14 & 14 & 14 & 14 \\
\hline
\end{tabular}

a Wounds significantly smaller after active stimulation than after sham (reatment $(P=.005 ; t$ test, one-tailed).

to improve, and $43 \%(6 / 14)$ healed completely.

After the 4-week double-blind portion of the study, 17 of the actively treated wounds continued to be treated. After a mean of 8 weeks' total treatment time, the wounds had healed to $23.6 \%$ of their initial size, on average. In addition, 38.5\% (10/26) had healed completely or nearly completely (>95\% healed) and $61.5 \%(16 / 26)$ had healed more than $80 \%$. The only treatment-related adverse effects re. ported were minor uncomfortable sensations in the wound (ie, tingling), which occurred in $15 \%$ of the patients (10\% of the control group and $20 \%$ of the treatment group).

\section{Dlecussion}

The results of our study supported our hypothesis and are in accord with the results of other studies ${ }^{1-4}$ showing that electrical stimulation enhances the rate and extent of healing of chronic wounds. Our findings are also in accord with those of investigations demonstrating that electrical stimulation can be used to promote healing of acute wounds induced in animals $5,7,8,19-21$ and to prevent necrosis from developing in ischemic skin flaps in humans. ${ }^{31}$

We found that, after 4 weeks of treatment, wounds in the treatment group healed to a mean of $44 \%$ of their initial size at a mean healing rate of $14 \%$ a week. During the same period, wounds in the control group healed to a mean of $67 \%$ of their initial size at a mean healing rate of $8.25 \%$ a week. Our results suggest that Kloth and Feedar were correct when they stated that the electrical stimulation treatment time required to satisfactorily enhance tissue healing does not need to exceed 60 minutes per day, 5 to 7 days a week. ${ }^{4}$ This treatment time is in contrast to the 20 to 42 hours of electrical stimulation treatment per week reported in other studies. ${ }^{1-3}$ We believe that treatment times between the 3.7 hours per week reported by Kloth and Feedar ${ }^{4}$ and the 7 hours per week reported in this study may be beneficial.

Further evidence supporting the use of pulsed electrical stimulation as an efficacious treatment of chronic wounds is provided by the 14 wounds in the control group of this study that were crossed over after 4 weeks to a nonrandomized active electrical stimulation treatment group. After 4 weeks of treatment, these wounds healed at a mean rate of $12.8 \%$ a week to $49 \%$ of their pretreatment size. Kloth and Feedar reported a similar response by a small group of crossover wounds in a previous study. ${ }^{4}$

That wounds in the control group healed to a mean of $67 \%$ of their initial size after 4 weeks is not surprising to us, because each of these wounds received an intensive amount of addi- 
tional care, including maintenance of a moist wound microenvironment as part of the sham treatment. Despite the improvement of the control group's wounds after 4 weeks, however, it is evident that the treatment group's wounds benefited not only from maintenance of a moist wound environment, but also from the electrical stimulation. This treatment protocol very likely accounts for the fact that $56 \%$ of the treatment group's wounds demonstrated good healing during the 4-week double-blind study as compared with only $33 \%$ of the control group's wounds.

We believe there is growing evidence that exogenous electrical currents can augment the healing process of dermal ulcers, perhaps by mimicking the body's own bioclectrical signals. We believe convincing evidence exists that electrically augmented healing of nonunion and delayed union fractures is best facilitated by invasive cathodal stimulation with between 5 and $20 \mu \mathrm{A}$ of direct current. ${ }^{32.33}$ Kloth and Feedari used a monophasic pulsedcurrent deviçe to deliver electrical stimulation at a frequency of 105 pps $(342 \mu \mathrm{C} / \mathrm{s})$ to wound tissue via the anode for 45 minutes daily, 5 days a week, and reported complete healing of nine wounds in a treatment group in 7.3 weeks. In our study, we also used a monophasic pulsed-currenc device to initially deliver electrical stimulation at a frequency of 128 pps $(500 \mu \mathrm{C} / \mathrm{s})$ via alternations of cathode and anode every 3 days for two 30-minute periods per day until the wound healed to stage II. Thereafter, the frequency was reduced to $64 \mathrm{pps}$ (250 $\mu \mathrm{C} / \mathrm{s})$, because we believed the higher pulse frequency might be harmful to the newly healed tissue. Although the healing rate of $14 \%$ a week after 4 weeks of stimulation in this study appears similar to the healing rates demonstrated in other studies, ${ }^{1.3}$ we cannot discern from our study what effect, if any, the two different pulse frequencies had on the rates of healing or the healing process.

Additional studies are needed to identify the mechanisms involved in the promotion of wound healing with electrical stimulation and to determine the stimulus variables that most efficaciously accelerate tissue repair. It is noteworthy that very few adverse effects attributable to electrical stimulation were reported during this study. Those that were reported were minor and of little consequence.

\section{Conclusion}

The healing rate of $14 \%$ a week of chronic wounds in the treatment group falls within the range of $13 \%$ to $46 \%$ reported in the literature. Although one group received actual electrical stimulation and the other group received sham electrical stimulation, the groups' treatment protocols were otherwise identical. We believe, therefore, that the differences between the healing rates of the two groups can be attributed to the electrical stimulation and that this study documents that electrical stimulation enhances healing of chronic ischemic wounds. We conclude that the use of electrical stimulation in the dosage and manner used in this study is a safe and effective way to treat stage II, III, and IV chronic dermal ulcers.

\section{Acknowledgments}

We thank the investigators and coordinators from the nine investigational centers that participated in this research project: Berkeley Convalescent Center, Moncks Corner, SC; Boulder Community Hospital, Boulder, Colo; Duke University, Durham, NC; Hogarth Hospital, Thunder Bay, Ontario, Canada; Marquette University, Milwaukee, Wis; Nassau County Rehabilitation Center, East Meadow, NY; North Charleston Convalescent Center, Charleston, SC; University of Colorado Medical Center, Denver, Colo; and Washington Hospital Center, Washington, DC. We also thank Katherine Miller, RN, for her assistance in standardizing measurement techniques; Dean Jeutter, $\mathrm{PhD}$, for his help in analyzing the stimulator output and waveform characteristics; and Harrison Stubbs, PhD, for assisting us with the statistical analyses.

\section{Reterences}

1 Wolcott LE, Wheeler PC, Hardwicke HM, Rowley BA. Accelerated healing of skin ulcers by electrotherapy: preliminary clinical results. Soutb Med J. 1969;62:795-801.

2 Gault WR, Garens PF Jr. Use of low intensity direct current in management of ischemic skin ulcers. Phys Ther. 1976;56:265-269.

3 Carley $P$, Wainapel $S$. Electrotherapy for acceleration of wound healing: low intensiry direct current. Arch Phys Med Rebabil. 1985: 66:443-446

4 Kloth LC, Feedar JA. Accelerarion of wound healing with high voliage, monophasic, pulsed cucrent. Phys Ther. 1988;68:503-508.

5 Assimacopoulos D. Wound healing promotion by the use of negative electric current. Am Surg. 1968;34:423-431.

6 Bigelow JB, Al-Hussein $S A$, Von Recum $A F$, Park JB. Effect of electrical stimulation on canine skin and percutaneous device: skin interface heaiing. In: Brighton CT, Black J, Pollack SR, eds. Flectrical Properties of Bone and Cartilage: Experimental Effects and Clinical Appli. cations. New York, NY: Grune \& Stratton Irk; 1979:289-310

7 Alvarez OM, Merzz PM, Smerbeck RV, Ea. glstein $W_{H}$. The healing of superficizl skin wounds is stimulated by extemal electrical cutrent. J Invest Dematol 1983;81:144-148. 8 Brown MB, McDonnell MK, Menton DN. Polarity effects on wound healing using eleciric stimulation in rabbits. Arch Phys Med Reba. bil. 1989;70:624-627.

9 Cuoper NS, Schliwa M. Electrical and ionic control of tissue ceil locomotion in a DC elec. tric field I Neurusci Res. 1985;13:223-244.

10 Erickson $C_{4}$ Nuccitelli R. Embryonic fibroblast motility and orientation can be influ. enced by physiological electric fields. J Cell Bitol. 1984:98:296-307.

11 Orida N, Feldman JD. Directional protrusive pseudopodia acrivity and motility in mac. rophages induced by exiracellular elecuric fields. Cell Motil. 1982;2:243-256.

12 Monguio f. Uther die polar Wirkung des galvanischen Stromes auf Leukuzyten. Z Biol 1933;93:553-557.

13 Fukushima $K$, Senda $N$, tnui $H$, et al. Studies on galvanotaxis of human neutrophific leukocytes and methods of its measurement. Med J Osaka Univ. 1953;4:195-208.

14 Dineur E. Note sur la sensibilitie des leukocytes a l'electricite. Bulletin Seances Soc Beige Micruscopic (Bnuxelles). 1981;18:113-118. 15 Sapyer PN. Bixclectric phenomena and intravascular thrombosis: the first 12 years. Surgeny. 1964;56:1020-1026.

16 Sawyer PN, Deurch B. Use of electrical currents to delay intravascular thrombosis in experimental animals. Am J Pbysiol. 1956; 187:473-478.

17 Sawyer PN, Deurch B. The experimental use of oriented electric fields to delay and prevent intravascular thrombosis. Surg fornum 1955;5:173-178.

18 Sawyer PN, gate JW. Hioclecuric phenomena as etiologic factors in intravascular throm. hosis. Surgery. 1953:34:491-500.

$19 \mathrm{Im} \mathrm{MJ}$, Lee WPA, Hoopes JE. Effect of electrical stimulation on survival of skin flaps in pigs. Phys Ther. 1990;70:37-40. 
20 Cruz NI, Bayrun FE, Suarez A]. Accelerated healing of full-thickness burns by the use of high voliage pulsed galvanic stimulation in the pig. Ann Plast Surg. 1989;23:49-55.

21 Stromberg BV. Effects of electrical cursents on wound contraction. Ann Plas Sung.

1988;21:121-123

22 Eberhardi A, Szczypiorski P, Korytowski G Effect of uranscutaneous electrostimulation on the cell composition of skin exudate. Acta Pbystol Pol. 1986;37:41-46.

23 Weiss DS, Eaglstęin WH, Falanga V. Exogenous electric current can reduce the formation of hypertrophic scars. J Dermatol Surg Oncol. 1989;15:1272-1275.

24 Harringlon DB, Becker RO. Electrical stim. ulation of RNA and protein synthesis in the frog eryhrocyce. Exp Cell Res. 1973;76:95-98.
25 Bassert CAL, Herrmann I. The effect of electrostatic fiekds on macromolecular synthesis by fibroblasts in vitro. I Cell Biol. 1968 39:9A. Abstract.

26 Bourguignon GJ, Bourguignon LY. Electric stimulation of protein and DNA synthesis in human fibroblasts. FASEB J. 1987;1:398-402. 27 Falanga V, Bourguignon GH, Bourguignon LY. Electrical stimulation increases the expression of fibroblasi receptors for transforming growth factor-beta. / Intest Dermatol. 1987;88:488A. Abstract.

28 Foulds IS, Barker AT. Human skin battery potentials and their possible role in wound healing. Br J l hermatol. 1983; 109512-522.

29 Barker AT, Jaffee LF, Vanable JW. The gla brous epidermis of cavies contains a powerfu battery. Am J Pbysiol. 1982;11:R242. Abstract.
30 Mash NI. Standards and protocols for pressure ulcer care. In: Krasner D, ed. Cbronic Wound Care: A Clinical Sounce Book for Ilealsbcare Professionals. King of Prussia, Pa: Health Management Publications Inc; 1990:97. 31 Lundeberg T, Kjartansson J, Samuelsson U. Effect of electric nerve stimulation on healing of ischaemic skin flaps. Lancet. September 24, 1988, pp 712-714.

32 Brighton CT. Treatment of non-union of the tibia with constant direct current. / Trauma. 1981;21:189-195.

33 Patterson DC, lewis GN, Cass CA. Treatment of delayed union and non-union with an implanted direct current stimulator. Clin $\mathrm{Or}$ thop. 1980;148:117-128. 